F. Ortúzar Vial.

\title{
LOS JESUITAS Y EL "NIÑO BIEN"
}

1 UMEROSAS patrullas de policía circulaban por los distintos barrios de la ciudad, acudiendo oportunamente a disolver los desórdenes callejeros, provocados por bandas de estudiantes y trabajadores. Las gentes salían a las calles, en demanda de lo inesperado, a correr riesgos, a gritar: jabajo Monseñor Sibilia!, a romperse la crisma con el vecino que se atreviera a contradecirles. Nadie se preocupaba de manifestar buen sentido. Cada cual aspiraba a tener el valor de sus opiniones y luchaba contra la fuerza armada, que no siempre lograba salir airosa frente a los garrotes, manejados con firmeza, y a las piedras lanzadas con certera puntería. No se hacían cálculos de probabilidades como ahora. La certidumbre del éxito nacía del nervio juvenil con que todos se entregaban a la acción, viviendo con deleite las exaltaciones eufóricas del idealismo. El concepto doctrinario impulsaba a unos cuantos, mientras la mayoría buscaba en estas circunstancias la ocasión de desahogarse, de descargar los nervios.

Los hombres luchaban en las Cámaras, en los perió- 
dicos; discutían en el club, peroraban en las asambleas. La muchachada se batía en las calles. Los que por aquel entonces no alzábamos más que un palmo del suelo, deseosos de mostrar nuestra hombría, vivíamos horas angustiosas, en el encierro del colegio, cuyas altas murallas nos aislaban del mundo exterior. Cada día, los internos esperábamos la llegada de los medio-pupilos, para conocer las novedades que en la ciudad se habían producido durante la víspera; mas las noticias que nos comunicaban no alcanzaban a satisfacernos y sólo servían de incentivo a nuestra curiosidad. La semana se nos hacía interminable; y el damingo, que era nuestro día de salida, nos preparábamos desde temprano, como quien se apresta para realizar un viaje por países desconocidos. Después de pasar las angustias consiguientes, por el temor de ser castigados y que fuera retardada por ello nuestra hora de libertad, llegabámos a nuestras casas, a leer los diarios, a conversar con nuestros parientes, a reunirnos con nuestros amigos, para salir luego a las calles y plegarnos, de soslayo, a cualquier grupo de estudiantes mayores, junto a los cuales solíamos correr más de una aventura.

Todos nuestros juegos infantiles, las imaginaciones de la edad, los combates de los piratas de Salgari, que leíamos con avidez en las horas de recreo, cobraban vida y valor real ante nuestros ojos. Nos parecía estar viviendo una epopeya. Hasta nosotros llegaba ese hálito de animoso idealismo, que nos impulsaba a combatir las maquinaciones de Monseñor Sibilia delante de los propios Padres Jesuitas, nuestros maestros.

Entretanto, la exaltación general subía de punto. Todo era incierto. Las noticias se circunscribían a las actuaciones oficiales, de que daban cuenta los diarios, y a lista de presos y de bajas, por obra de los caballazos de la policía, que trasmitía la tradición oral. Los rumores se entrecruzaban, como boca-calles de una ciudad ideal, superpuesta a nuestra aldea santiaguina. 
Y nosotros sentíamos transcurrir las últimas horas de libertad dominguera, con la pesadumbre de los días de encierro y aislamiento que nos esperaban.

Mi madre, comprendiendo nuestro estado de ánimo, y deseosa de que no interrumpiéramos nuestros estudios, de que nada nos perurbara y alejara de ellos, r c s atiborraba de buenos consejos cariñosos, presentándonos imágenes halagüeñas del porvenir que nos esperaba si nos sometíamos a la disciplina y dando tiempo al tiempo esperábamos que llegara para nosotros la hora de la acción. Por desgracia, más tarde no hemos visto realizadas esas ilusiones; nuestro espíritu perteneció a una generación más fervorosa, más desprendida e idealista que aquella en que formamos, por razones de tiempo. Después de haber soñado con la acción, hemos tenido que conformarnos con el buen sentido

Regresábamos al colegio con el corazón del tamaño de una avellana, pensando en la monotonía de las clases, en la rutina que nos esperaba, en la voz gangosa con que habría de saludarnos el hermano portero, en el silencio de los dormitorios. Una secreta esperanza acompañaba nuestros pasos hasta llegar a la puerta de nuestro Colegio; hubiéramos querido que de una esquina surgiese lo inesperado, lo que nos impidiera recogernos esa noche, siquiera esa noche. Pero generalmente, después de cariñosas despedidas y de recomendaciones maternas, la puerta se cerraba tras de nosotros, como una sentencia inapelable, como un mal sin remedio.

Una noche nuestras ilusiones crecieron. Al enfrentar la calle San Ignacio, desde la Alameda de las Delicias, nos encontramos con que toda ella estaba cubierta. por fuerzas de caballería, que formaban un cuadro alrededor del Colegio. Las tropas, en posición de alerta, no se habían desmontado, $\$$ y los caballos mascaban impacientes los frenos. La calle Alonso Ovalle, igual- 
mente resguardada, había sido vedada al tránsito; sólo se permitía pasar por ella a los alumnos de los jesuitas. El Colegio de éstos, amplio, sombrío de aspecto, con sus ventanas cerradas, la puerta apenas entreabierta, daba una impresión de silencio, de serenidad; parecía un mundo diferente, ajeno al mundo a que pertenecía la calle. Las dos torres, erguidas, semejaban dos estatuas, seguras de sí mismas. En ellas, el reloj parecía desentenderse de la actualidad, midiendo la inmensidad del tiempo. Junto a él, grabado en piedra el famoso lema: ad maiorem Dei gloriam.

Nosotros esperábamos, con mayor avidez que nunca, lo insólito. Creíamos que esa demostración de fuerza, esa mise-en-scene, amedrentaría a nuestra madre. Pero ella era más valerosa de lo que creíamos. Nos repitió sus consejos, nos animó a renovar las tareas colegiales, nos hizo ver que estábamos a cubierto de cualquier emergencia, que nada debíamos temer. $Y$ nosotros, después de esto, tuvimos que despedirnos y penetrar en ese otro mundo del colegio.

Más tarde supimos que nada había acontecido. Es decir, que ningún rumor había alcanzado la categoría de realidad. Pero en cambio conocimos el precio que había pagado nuestra madre por su serenidad. No bien hubo regresado a casa, recibió la visita de un pariente, que le manifestó el peligro en que podíamos hallarnos. Según el decir de las gentes, Monseñor Sibilia se había refugiado en los jesuitas y los estudiantes se preparaban para asaltar la santa casa y apresar al Internuncio. En vista de tan alarmantes presagios, mi madre, se dirigió nuevamente a la calle Alonso Ovalle. Llamó en el colegio y solicitó hablar con el Prefecto, que lo era en aquel entonces el Padre Angla.

La figura angulosa de éste se perfiló en una de las puertas del zaguán. Por encima de sus lentes, miraba a sus interlocutores, mientras se desarrollaba entre ellos el siguiente diálogo: 
-Padre, me han dicho que Monseñor Sibilia se haalojado aquí.

- Puede ser, señora-contestó el jesuita, con su voz nasal, siempre mirando por encima de sus anteojos. tes....

-Y dicen que van asaltar el Colegio los estudian-

También puede ser....

Es que en tal caso yo quiero llevarme mis niños.... Eso no puede ser, señora....

Pero es que permaneciendo aquí están expuestos a un peligro....

-Puede ser....

- Y si los estudiantes han preparado el asalto la policía no va a ser suficiente para detenerlos y van a lograr lo que se proponen....

-Puede ser....

-Es que entonces yo me llevo a mis hijos....

-Eso, le he dicho ya, no puede ser... Nuestra regla es inflexible. Los alumnos ya se han recogido y no pueden abandonar el Colegio. Si usted lo desea, los retira mañana, pero ya no podrían ser educados en el establecimiento....

-Pero, Padre, si estos niños corren algún peligro....

- Dios no lo permitirá. Los hijos de San Ignacio han de permanecer en sus puestos.

¿De modo que se quedarán aquí? ¿No asaltarán el colegio? ¿Está aquí Monseñor?

- No lo sé. Ignoro si está. Ignoro si van a asaltar el Colegio.

-Yo me llevo a mis hijos....

- No puede ser......

El Prefecto no abandonaba su entonación nasal. Impasible, continuaba mirando la desesperación de mi madre por encima de sus anteojos.

$\mathrm{Y}$ en el colegio permanecimos esa noche. Esa y las siguientes.... .

No hubo peligro en verdad para nosotros. ¿Cómo 
se resolvió la situación? Lo ignoro. Pero si lo hubiera habido, si el Colegio hubiera sido asaltado y en pleno asalto, mi madre nos hubiera ido a buscar, a mis hermanos y a mí, también le hubieran contestado: "no puede ser....»

\section{$\forall$}

Los Padres jesuitas, conforme al método de San Ignacio, habían analizado de antemano nuestra situación. Al contemplar el panorama de la sociedad, habían recibido una generación; la habían estudiado concienzudamente, procurando fijar, en términos absolutos y concretos, la misión que le había de corresponder más tarde; y después de esto, no pensaban más, sino que ejercitaban sistemáticamente los medios de conseguir el fin que se habían propuesto. Quiero decir que seleccionaban los alumnos que recibían y estudiaban el papel que estaban llamados a desempeñar. Los educaban, de acuerdo con el ideal que se habían forjado respecto de ellos, independizándose por entero de la vida, de las contingencias, de las imposiciones del momento.

En el caso que he relatado, se nos consideraba niños católicos que debían mantener el vínculo de solidaridad con el Colegio y la Religión, sin consideraciones accesorias, sin tomar en cuenta nuestra edad, sin que para nada pesaran las angustias que habían de sufrir nuestras familias, con la frialdad de la lógica aparente con que nos repetían a diario: "¿de qué vale todo, de qué vale la vida, de qué sirve la felicidad, si al fin se pierde el alma?

La selección mencionada se operaba por sí sola, merced a la influencia de varios factores. Uno de ellos, y acaso el principal, consistía en el costo de la pensión escolar. Los otros derivaban de la religiosidad y el sno- 
bismo de las clases altas. Debido a esto, cada uno de los alumnos era una especie de resumen viviente de historia nacional. Para no citar más que un caso conocido por mí, puedo referirme a un niño cuyos antecedentes familiares lo relacionaban con don Manuel Bulnes, don Aníbal Pinto, el Conde Toro y Zambrano, don Andrés Bello y toda una legión de colaterales y afines de brillante actuación pública. Y así como éste la mayoría.

Los jesuitas valorizaban este hecho y procuraban su extensión, por medio de relaciones sociales y de cierto género de pequeñas contemplaciones de que gozaba el alumno que era descendiente de hombres ilustres. Por otra parte, el plan pedagógico de estos religiosos, basado en las máximas de Gracián ( $E l$ discreto) y en otros principios propios de la Compañía de Jesús, tendía a la formación de clase dirigente. Esto es, orientaba la educación en un sentido eminentemente humanístico, que inculcaba en el ánimo del niño la idea del papel preponderante, que por su genealogía y su situación económica estaba llamado a desempeñar. Recuerdo, a este propósito, que una vieja sirvienta, cuidadora de uno de mis compañeros, al ser preguntada acerca del porvenir que le esperaba al niño que tenía a su cargo, respondía sin vacilar que llegaría a ser obispo, "o, cuando menos, Presidente de la República». Y esto lo creía también mi amigo, lo creíamos todos, sin ver para nosotros, en el futuro, más que un estrado sobre el cual luciríamos el birrete morado o la banda tricolor.

El Colegio de San Ignacio era una especie de colegio de nobles. Gracias a ello, los niños que allí se educaron demostraron con el tiempo analogías con los miembros de aristocracias caducas, cuyo espíritu frívolo, cuyo egoísmo y falta de iniciativa agravan los males históricos que sufren en la hora actual algunas naciones monárquicas. 
Recordar a quienes ejercieron funciones públicas, en el período comprendido entre el suicidio del presidente Balmaceda y el primero de los pronunciamientos militares, equivale a repasar el Catálogo de Alumnos, que constituía deliciosa novedad gráfica a principios de cada año. Los que llegaron a ser Ministros, Senadores, Consejeros de Estado y aquellos otros que lograron categoría de figurones, sin título oficial que justificara su magnífica prosopopeya, habían registrado sus nombres en aquel anuario estudiantil; alguno de ellos cursaba el sexto año de humanidades, mientras yo me empinaba al final de la fila que formaba la tercera preparatoria, o mejor la elemental inferior segunda sección, como se la denominaba en 1911; los hijos o los sobrinos de otros eran mis compañeros; y el nombre de casi todos figura en la lista del banquete en que se reunen anualmente los ex-alumnos de San Ignacio. Así, casi todas las personas que descollaron políticamente, durante aquel tiempo, me son familiares. Es natural que por esto me explique, mejor que cualquier otro, la exactitud con que se define ése como el régimen de la gente conocida y conozca por qué toda gestión se traducía en empeños y el apellido vasco constituía un mérito administrativo. La camaradería estudiantil, ampliada por las alianzas de familia, persistía en las esferas de gobierno. Los gestores no hacían más que apelar a viejos afectos. Las ceremonias oficiales reunían a las mismas personas que habían ensayado ademanes de mesurada apariencia en las reparticiones de premios, que con tanta solemnidad tenían lugar en el Salón de Actos de la calle Alonso Ovalle. Y no es de extrañar que en el continuo trato entre camaradas aceptaran los políticos de aquel tiempo combinaciones y procedimientos que más tarde han parecido cosa de chacota a algunos señores graves.

Dada la situación social de los alumnos y esa figuración lograda por sus antecesores, era lógico relacio- 
nar la actualidad nacional con el Colegio. Cual más, cual menos, todos esperábamos que las generaciones venideras se hallaran, con respecto a nosotros, en idéntica situación.

Los jesuitas nos tomaban de la clase dirigente y nos educaban para ser directores. Por nuestra parte, comprobábamos el éxito logrado por nuestros ascendientes y colaterales, y como recibíamos idéntica educación que ellos, creíamos buenamente que habíamos de alcanzar igual notoriedad. De acuerdo con su lógica los hijos de San Ignacio, analizada nuestra situación, definido el propósito que podía perseguirse, esto es, establecida la misión que a juicio de ellos había de correspondernos y la educación que habíamos de recibir para poder llenarla cumplidamente, ponían manos a la obra, sin tomar en cuenta lo contingente, en forma esquemática, sin ápice de humanidad.

Los alumnos vivíamos auxiliados por una fuerte organización que nos lo procuraba todo. Se nos educaba para teóricos. Dentro del establecimiento, nada hablaba a nuestras mentes infantiles de las dificultades de la vida. En él se respiraba una atmósfera de comodidad, de bienestar. Cuidadosamente se pintaban todos los años las murallas y pilares que circundaban los patios, y eran barnizados los escritorios, encerado el piso de las clases, otorgando siempre una importancia trascendental a la presentación externa del Colegio y sus pupilos. Todo era allí limpio, pulcro, cómodo; la comida abundantísima, de calidad superior; la servidumbre numerosa y disciplinada; esmerado el cuidado con que se atendía a los detalles materiales. Y esto por medio de una organización metódica, cuyo mecanismo desconocíamos los alumnos. No disponíamos de lujo, si como tal se entiende lo superfluo; pero sí teníamos el lujo de poseer todo lo necesario, preparado convenientemente, en el momento en que lo requeríamos. No caía un cuadro, no se quebraba un vidrio, no 
se estropeaba un escritorio, sin que fuera refaccionado o repuesto al instante, sin mayores requerimientos (1). Los niños veíamos que todo marchaba a maravilla, sin comprender cómo ni por qué. En nuestras casas, por otra parte, hacían esfuerzos sobre-humanos para que nada nos faltara, para que pudiéramos alternar y rivalizar con nuestros compañeros. Ignorabámos el valor del dinero; no nos preocupábamos de saber lo que cuesta cada cosa. Todo lo teníamos, como por obra y gracia de una varillita mágica.

A juicio de los jesuitas, estábamos en el colegio para estudiar y nada más que para éso. Toda otra tarea era encomendada a uno del oficio. Al leer nosotros las vidas de santos, y conocer por ellas la tranquilidad con que algunos varones veían llegar los instantes de apremio diciéndose confiados: «Dios proveerá», no hacíamos más que repasar una verdad que nos parecía inconcusa.

De este modo, Ios ex-alumnos de San Ignacio sólo nos consideramos aptos para las llamadas carreras liberales. Llegamos a mayores, huérfanos de toda iniciativa, con refinamientos principescos, con cierta molicie espiritual, desconocedores del valor de la vida. Al-

(1) Esta presteza en acudir a remediar desperfectos constituye una práctica de trascendental influencia psicológica. Merced a ella veíamos confirmarse nuestra idea de que todo se arregla solo y nada tiene importancia. Adquiríamos la seguridad de lo que pudiéramos llamar nuestra fortuna y nos acostumbrábamos a no carecer de nada.

Por informaciones de personas que me merecen absoluta fe, conozco el caso opuesto, que se producía en algunos colegios fiscales, durante la misma época. El Instituto Nacional, por ejemplo, con ser uno de los establecimientos mejor atendidos, cargaba en cuenta a sus alumnos el valor de los objetos que destruían y su administración tardaba en remediar el daño lo que una gestión en oficina pública. Ateniéndome a estos informes, puedo señalar al Liceo Barros Borgoño (siempre durante la misma época), como un caso típico de abandono, suciedad y miseria. Poséa éste salas estrechas y mal iluminadas, servicios higiénicos rudimentarios, instalados al descubierto, menguado patio que en invierno se transformaba en barrizal, murallas inclinadas y reblandecidas por la humedad, empapelado sucio y desprendido, bancos hechos trizas; en fin, todo lo necesario para producir en el alumnado una deprimente impresión. Niños y profesores sabian cuán inútiles habian de ser sus esfuerzos para remediar tales males y hacían lo que hace un chileno en tales casos: dejarse estar. 
gunos llegaron a ser hombres de gobierno y mostraron entonces su inepcia en materias administrativas. Derrocharon caudales, se mostraron insuficientes en el sentido burocrático, familiarizados como estaban con la idea de esa varillita mágica que todo lo remedia a tiempo. Para ellos, el consejo administrativo del Colegio, el que mandaba componer lo roto, pagar las cuentas y hacer las provisiones, se transformó en el inmenso mecanismo del Estado, con iguales funciones.

Yo recuerdo que nada tenía importancia, para nosotros los colegiales; hacíamos colecciones de objetos robados al establecimiento, solicitábamos, para desperdiciarlas, mayor cantidad de raciones que las necesarias; disponíamos antojadizamente de todo, sintiéndonos dueños y señores de la casa.

Los niños bien, que llegaron al Gobierno después de haber sido educados en esta forma, no podían proceder de otra manera con Papá Fisco. Los que no alcanzaron tal encumbramiento, se perdieron....

San Ignacio no formó el tipo burgués, que vive feliz en aurea mediocritas, y que es a conciencia un hombre de bien. Sólo formó al político brillante, ramplón a veces, y al tarambana. Los que no alcanzaron los halagos de la popularidad y del triunfo, malgastaron sus

Muchos de los que han sido educados en establecimientos de tan vergonzosas apariencias se han abandonado a sí mismos, se han congraciado con la miseria y la mugre. Los colegios fiscales han contribuido al desgreño racial de que habla Pérez Rosales.

La influencia de tales circunstancias es apreciable en los cursos universitarios. En ellos se diseñan claramente los grupos; se apartan unos de otros y se distinguen por características especiales. Uno de ellos, formado por los bachilleres egresados de San Ignacio y otros colegios por el estilo, atildados, petimetres, con calma para estudiar, con tiempo disponible, con cierto aire de hombres de mundo que asisten a la Universidad con displicencia elegante, como quien va a una fiesta un poco aburrida, en la que hay que presentarse por obligación. El otro grupo formado por los estudiantes de liceos, santiaguinos o provincianos, pobres, desgreñados, inquietos, atormentados por la necesidad. estudiosos en su mayoría, fiando el porvenir al empeño con que asisten a las clases. En términos generales: de un lado, el hombre seguro de sí mismo, que sabe cuál será su porvenir, en el estudio de un pariente acreditado; dél otro, el industrioso, el busquilla, que quiere apresar el éxito a fuerza de constancia. 
vidas. Empezaron figurando socialmente; algunos continúan la tradición ocupando asientos en el club y paseando su aburrimiento por los sitios elegantes. Los otros, los que tenían demasiado talento para conformarse con las satisfacciones de lo $s n o b$, han visto desdorarse su bohemia y más de alguno vive en la sombra.

Los jesuitas nos proporcionaban en su establecimiento la tranquilidad de que goza el laboratorista, aplicado al microscopio mientras un mozo le acarrea los materiales que necesita, un cobrador recauda sus ganancias y una mujer organiza la vida en su hogar. Pero de la tranquilidad a la molicie no hay más que un paso. El primer efecto de este sistema del confort material, de de la despreocupación de la vida, era nuestra disipación espiritual. Como niños que éramos, no disponíamos de la disciplina necesaria para contraernos al estudio. Quienes se educaron conmigo, o antes que yo, pero en el mismo sitio, no pueden decir que hayan conservado del colegio más que ciertas modalidades psicológicas adquiridas en él. No estudiábamos. Los po$\cos$ que lo hacían, no asimilaban, por la preferencia que se otorgaba a los ejercicios de memoria, por deficiencias del sistema y de los profesores.

El método antiguo era el establecido y la norma consistía en repetir la materia, como loros, hasta que se grababa y podía decirse de punta a cabo, sin tropiezos. Compañero tuve yo que en un examen, al hablar de los Capetos, empezó con las mismas palabras del libro: "Como decíamos en el capítulo anterior....»

También tuve un profesor de aritmética, el Padre Ferrater, que sin tomarse mayor trabajo explicaba 
siempre en la pizarra el mismo problema cuya solución ofrecía el libro. Así su clase era enteramente inútil. Y si alguna vez, deseosos de interesarnos en ella, le preguntábamos la razón por la cual ejecutaba tal o cual operación, nos respondía invariablemente: «esta tarde te diré por qué...», lo que en buen romance equivalía a una sentencia de dos horas de arresto vespertino. El Padre Ripoll, que trataba de enseñarnos Historia Moderna, quiso que aprendiéramos este ramo por medio de cuadros sinópticos y nos pedía que, de acuerdo con su sistema, compendiáramos la historia de Napoleón en cuatro títulos, los cuales habían de ser: Jena, Wagram, Austerlitz y Waterloo. Con ello cumplíamos nuestros deberes de aplicación, pero continuábamos ignorando la vida del Gran Corso. En clase de Historia de América y Chile, el Padre Correa Valenzuela sólo nos exigía orden y compostura. Pasaba la materia rápidamente, hurtando el cuerpo a las interrupciones, que él llamaba «preguntas capciosas». Y cuando algún alumno solicitaba de él que ampliara sus informaciones sobre determinado punto o que precisara una fecha, le decía: usted, fulano, que es de familia criolla y vieja, sea consecuente con su profesor, lo que equivalía a rogarle humildemente que lo dejara en paz.

Existía en el establecimiento una especie de delirio de persecución que se justificaba algunas veces. Se decía que todos los profesores universitarios que eran examinadores pertenecían a la Masonería y procuraban reprobar el mayor número posible de alumnos. De ello se defendian los padres auxiliando a los examinandos en ese trance, haciendo causa común con ellos, por medio de subterfugios que llegaban hasta lo inverosímil. Una vez, por ejemplo, en examen de Historia de América y Chile, un niño incluyó en la lista de Presidentes el nombre de don Antonio Varas. El examinador, sorprendido por la magnitud del disparate, le llamó la atención en forma un poco 
brusca; y entonces, el profesor, que en aquel año lo era el Padre Galarza, para defender al niño, repuso al examinador: Sin embargo, señor, hay opiniones.

Tales situaciones eran producidas por el deseo de no echar mano de profesores extraños a la congregación. En la imposibilidad de completar el número de maestros, obligaban a tal o cual religioso a estudiar una materia durante las vacaciones para enseñarla al año siguiente. Aunque justo es decir que también había algunos profesores magníficos: los de Filosofía, Física, Química, Geometría, Cosmografía, Historia Natural; buenos especialistas que perdían su tiempo al querer traspasarnos sus conocimientos, ya que el sistema antiguo nos obligaba a pasar rápidamente las materias y rendir exámenes finales después de sólo un año de estudio.

Todo esto ha influido para que los ex-alumnos de San Ignacio, al salir del Colegio, tuviéramos que repasar las humanidades privadamente. Los que tal no han hecho, conservan un barniz muy superficial de cultura, pero ninguna idea precisa. La única huella que ha dejado en ellos la educación de los padres jesuitas reside en la idiosincrasia formada por ella.

Por lo demás, en aquel establecimiento, para figurar entre los alumnos distinguidos no necesitábamos gran cosa del estudio. Se ascendía por méritos ajenos al esfuerzo personal. He dicho anteriormente que nuestros profesores tenían muy en cuenta los antecedentes familiares de algunos niños. Merced a esto quienes tenían relación estrecha con personajes de actualidad lograban cierto favor en los concursos, así como aquellos que demostraban acendrados sentimientos de piedad y eran miembros de la Congregación Mariana.

Pero quedaba otro recurso, al alcance de todos y por todos ejercido. La cuestión en el Colegio no se reducía a estudiar para saber, por amor a la ciencia, por curiosidad intelectual, sino que consistía en estudiar 
para figurar. Lo esencial de la educación que recibíamos en San Ignacio residía en la emulación. Y ésta se traducía en una serie de esfuerzos sostenidos por el amor propio, sujeto a exterioridades y al halago de manifestaciones públicas. Ningún aliciente moral encontraban los alumnos. No había más que exhibiciones espectaculares. Las clases se hallaban divididas en dos bandos: Roma y Cartago. Los niños adquiríamos espíritu de casta y defendíamos con ardor al bando a que pertenecíamos. Acaso allí nacieron las aptitudes de algunos que fueron más tarde, en el Congreso, miembros disciplinados de un partido político, gobiernistas $\mathrm{u}$ oposicionistas a outrance. Cada uno de dichos bandos poseía cuatro primates: Cónsul, Legado, Abanderado y Decurión, quienes gozaban de ciertas franquicias y prerrogativas. En ello vemos una imagen de la jerarquía que posee la nobleza y de los cargos ministeriales decorativos a que son tan aficionados los políticos republicanos. Los puestos indicados eran ocupados por los alumnos que obtenían mejores notas en las composiciones mensuales. Pero se podía llegar a ellos por medio de desafíos, o contrapuntos, que se realizaban semanalmente. Este procedimiento, que parecía destinado a estimularnos en el estudio, no hacía más que agudizar nuestra dialéctica y sutilizar nuestras argucias polémicas. En los desafíos no triunfaba el que conocía mejor la materia de que se trataba, sino el de argumentación más rápida, el más aficionado a los detalles. Y como es natural, este género de lucha se desplazaba al terreno personalista. Surgían las disidencias. Los rencores eran frecuentes. Se recurría a todas las «martingalas» posibles, a las preguntas capciosas, a las sutilezas metafísicas. Entre vencedores y vencidos se creaba una suerte de enemistad política. Luego nació el sport de derribar Cónsules. Se formaron coaliciones. Todo igual a lo que vimos más tarde, al dejar de ser niños. Idénticos procedimientos en casos de mayor 
trascendencia: coaliciones cerradas, disidencias insalvables, derrocamiento de Ministerios por simples juegos de dialéctica.

De acuerdo con la educación que recibimos, hemos creído después en los teóricos y en el valor de la oratoria. Más aún, gracias a la influencia de todo esto nos acostumbramos a no analizar los conceptos, conformándonos con dos o tres denominaciones pomposas.

La mayor de nuestras ambiciones consistía en hacernos aplaudir, recitando o cantando, en las proclamaciones de dignidades que se efectuaban mensualmente con toda solemnidad. Aspirábamos también a lucirnos en ellas con la banda de los Cónsules-azul para el cartaginés, roja para el romano-, así como nos mostrábamos arrogantes, ante las enternecidas miradas de nuestros familiares, con el pecho constelado de medallas, durante las reparticiones de premios. En lo que pudiéramos llamar la vida privada, esto es, en las actividades propiamente escolares, hallábamos incentivo excitante en los famosos desafíos de que he hablado.

Durante el mes de Septiembre llegaban al máximum nuestras aspiraciones; nos presentábamos magníficamente, ataviados con costosísimos uniformes y armados militarmente, en una revista de gimnasia. Adoptábamos entonces el aire de salvadores de la patria. Nos condecoraban, por concepto de agilidad en el trapecio, de ligereza en los saltos, de disciplina en las filas. Nos sentíamos héroes.

Todas estas cosas, amalgamándose en nuestro fuero interno, imprimieron una modalidad en nosotros. Gracias a ellas adquirimos nociones acerca de la patria, del bien, de la humanidad; nociones bien distintas, por cierto, de la realidad. Las comodidades de que siempre gozamos, la seguridad que adquirimos de que todo se lograba como por arte de encantamiento, produjo en nosotros la molicie espiritual. Nos convertimos, sin 
advertirlo, en lo que con propiedad se ha llamado el niño bien. La mayoría de los ex-alumnos de San Ignacio han sido jóvenes muy elegantes, desconocedores de la vida, sin espíritu de empresa, sin noción de lo práctico. Se han asilado en la carreras liberales. Por obra y gracia de algún pariente bien colocado, poseen un estudio que proporciona lo indispensable para vestirse y pasear; el resto lo paga, generalmente, el papá. Algunos han llegado a cargos públicos importantes. En ese caso han considerado al Fisco como un organismo administrativo destinado a proporcionarles lo que les viniera en gana, con una idea declamatoria y hueca del deber y la Patria. Sin nociones de eso que los norteamericanos han llamado «espíritu de servicio *. Familiarizados con los que fueron hombres dirigentes por espacio de un largo período, se han acostumbrado a tratarlo todo sa lo amigo». Como las generaciones anteriores fueron educadas en idéntica forma y poseían idiosincrasia análoga, se generalizaron las prácticas viciosas y se llegó, lógicamente, a la podredumbre social y política que justifica la situación actual.

Los jesuitas no han abandonado sus prácticas. Continúan seleccionando los alumnos que han de recibir en su colegio, procurando que ellos pertenezcan a la clase dirigente. En mi tiempo, el anuario escolar estaba poblado de apellidos vascos, que eran los predominantes en la vida nacional. Hoy se encuentra plagado de nombres que pertenecen a la industria y el alto comercio. Influencia por influencia, considerando caduca la que ejercieron los apellidos, cultivan hoy la del dinero. Y es sensible. Los hijos de industriales y comerciantes tienen en sus hogares la mejor escuela y el más alto ejemplo. Puede presumirse que poseen, en potencia, capacidad de trabajo, espíritu de iniciativa y otras virtudes que se engendran y desarrollan junto al esfuerzo personal. Y si en el Colegio de San Ignacio van a ser educados como en colegio de nobles, perderán 
sus buenas cualidades, por falta de ejercicio, se crearán necesidades ficticias, se transformarán en seres complejos. Y pudiera ser que llegaran a malograrse y convertirse con el tiempo en otros tantos niños bien, de cultura insuficiente, de psicología perjudicial. 